\title{
A study on the Cultivation of College Students' Self-discipline in the Network in the Age of We-Media
}

\author{
JIANG, Jia \\ Department of Clinical Medicine, Xuzhou Medical University, Xuzhou 221004, Jiangsu, P. R. China \\ email: 26423740@qq.com
}

Keywords: We-Media; College Students; Network Self-discipline

\begin{abstract}
With the continuous development and improvement of information technology, the emergence of We-Media has brought great convenience to the study and life of college students. They are not only the information receivers but also the disseminators. In this circumstance, they must strengthen their self-discipline, especially the awareness of network self-discipline, so that they could make good use of the convenience brought by the media to enhance their overall quality. This article starts with the connotation and characteristics of college students' self-discipline consciousness, followed by analysis of the challenges in the age of We-Media, and ends up with corresponding cultivation strategies.
\end{abstract}

\section{Introduction}

With the rapid development of information technology, the We-Media has achieved unprecedented development. With more cultural awareness, college students are more liable to accept new things with full enthusiasm. As a result, it is easier for them to become one of the groups affected by the We-Media. At a critical stage during their lives, they are likely to be exposed to risks in knowledge acquisition, self-cognition and moral cultivation. The way to effectively deal with the negative impacts of We-Media on college students has become a concern for colleges and universities.

\section{An analysis of the connotation of college students' self-discipline}

Consciousness about network self-discipline refers to that based on the needs and cognition of the overall interests of the network society, network users voluntarily agree with the network norms, and are able to practice the ideological concepts according to their particularity.

First, from the perspective of source, network cuts both ways. It not only brings convenience but also causes disorder which will exert a profoundly negative impact. So people began to realize that network behavior needs to be regulated and managed.

Second, in terms of the content, the development of conscious about network self-discipline is a process of people's internal transformation of network social norms. The so-called norms mainly refer to the criteria of common behavioral expectation formed during development. There are two main types of abiding forces: one is mandatory network specifications, such as legal rules and regulations; and the other is non-mandatory network specifications, such as online habits and group norms of related networks users.

Third, in terms of the process, the consciousness about network self-discipline is formed in the process of using the network. The management of network behavior can never be achieved without laws and regulations. Through the implementation of these measures, anomie can be punished and the order in the network society can be established. 


\section{The characteristics of college Students' self-discipline}

\subsection{Self-consciousness}

Self-consciousness refers to the awareness and subsequent actions taken by the relevant network users in the recognition of network norms and network society. Network behavior is primarily embodied in a rational understanding of the network society and the norms, and then it generates identity and recognition. On this basis, uses can make choices and decisions about their own network behavior.

\subsection{Internalization}

The internalization process often requires two basic conditions. One is that the network users must have a fairly clear and clear rational cognition, and can truly combine their own needs with the interests and needs of the network social. The second is that the users should transform and apply the external norms to the individual's network behavior.

\subsection{Openness}

It is mainly embodied in two aspects. One is that the formation of network self-discipline consciousness can not only stay at the level of self-improvement, but also be tested and improved in the behavior of network users in order to achieve internalization and improvement. The other is that the cultivation of online self-discipline consciousness of users is often influenced by other groups, especially their peers.

\subsection{Practicality}

On the one hand, the development of network self-discipline consciousness comes from the needs of network social practice, because all kinds of problems in the network society require relevant normative policies to be introduced, and then corresponding network regulation to be carried out. Consciousness about network self-discipline is an important manifestation of compliance with network regulations. On the other hand, college students' self-discipline consciousness has a practical orientation in the process of formation. The formation of self-discipline consciousness requires the users to continuously improve their own self-discipline quality.

\section{The challenge to college students' self-discipline in We-Media age}

\subsection{Internal challenges}

First, the impact of college students' emotions. At a certain age, the physiology and psychology of Chinese college students are in rapid transformation. In this case, many negative emotions such as anxiety and depression are likely to harass, which will cause serious problems to students' life and study.

Second, the influence of college students' mind. As the new power for social development students have broad vision, active thoughts and rich ideas. With these characteristics, they are good at expressing their own personality, but at the same time, they might go the wrong path.

\subsection{External challenges}

Firstly, the way information is transmitted and received by the new media era has changed dramatically. Individuals in the era of new media have gradually transformed from a mere recipient of information to a transmitter of information. Students who are not mature enough are increasingly dependent on the Internet. Some short and refined language styles in the network are in line with the students' psychological characteristics. Therefore, the convenience of the network makes it difficult for students to control their time, which will profoundly affect their and life.

Second, massive information floods the Internet. Everyone is the transmitter and recipient of information. In addition, the current online world is still full of flawed information, because of the 
lack of careful editing and strict review. It has caused many obstacles to information selection and utilization.

\section{Strategies of cultivating self-discipline consciousness among college students in the age of We-media}

\subsection{Active guidance through the new media platform}

The pace of information dissemination, especially in colleges and universities is keeping up with the development of the times. There are a variety of emerging information dissemination channels such as QQ, Weibo, campus websites, electronic newspapers, and WeChat public platforms. They cover a wider range and reach more people, and the speed of information dissemination is getting faster and faster, which enables students to receive information in a more convenient way. It still needs improvement, and the use and regulation of We-Media use entails regulation. At the same time, We-Media can be used for the education of network self-discipline.

First, the use of We-Media for student network self-discipline education should be carried out in an equal and proper manner. The specific educational content should be embedded in the media contact behavior of students subtly.

Second, colleges and universities should actively create distinctive platform in the era of media, and should highlight peculiarity in terms of information transmission and writing style, rather than the homogeneity and repetition of information.

Third, it is necessary to further strengthen the interaction between students and the media, and to strengthen the media's own appeal. Only in this way can the school media provide good guidance to students, making college students more self-disciplined in the media environment.

\subsection{Enhancement of the concept of educational responsibility and ideological and political education}

First, universities should actively train terms with strong technical and network qualities, which can actively maintain the WeChat public platform and official website of universities, as well as disseminate positive ideas and education through these platforms in order to fully fulfill the role of We-media in universities.

Second, in the era of the We-media, universities should keep pace with the times, innovate the concept of education, and learn to use the internal institutions to carry out ideological and political education, so that the core values of socialism become the main theme of the current media management of universities. Meanwhile, the education of network self-discipline should be integrated into the education, to motivate students to strengthen self-discipline in a positive atmosphere.

\subsection{Use of methods that are acceptable to students}

With We-media, universities should make full use of the effectiveness, attractiveness and timeliness of We-media to strengthen the interaction between students and schools, understand the students' ideological dynamics, and strengthen the communication and interaction between students and schools. In this process, mainstream values can have a subtle influence on students, which enables them to distinguish between the right and the wrong and enhance their self-discipline.

\section{Summary}

In general, college students are exposed to more and more information in study and life, and the world they face is more complicated. Various aspects should be considered to guide students to enhance their consciousness of network self-discipline with innovative approaches, so as to cultivate high-quality talents that truly meet the needs of the times. 


\section{Acknowledgements}

This research was financially supported by the Funds for Top-notch Academic Programs Project of Jiangsu Higher Education Institutions, China (Grant: NO. PPZY2015B161) and the Research Funds for Jiangsu University Philosophy and Social Science, China (Grant: NO. 2017SJB0986).

\section{References}

[1] CAO, Xiaoyuan. The negative Influence of internet on college students' ideological and political education and its elimination path, Education Review,vol. 4, pp. 98-100, 2016.

[2] LI, Chunshan. Problems and countermeasures of college students' network moral selfdiscipline in the Age of Media, Legal System and Society, vol. 25, pp. 228-229, 2014. 